\title{
List of keynote speakers, panellists, moderators
}

(C) European Association for Predictive, Preventive and Personalised Medicine 2011

KEYNOTE SPEAKERS, PANELLISTS \& MODERATORS

MAIN STAKEHOLDERS

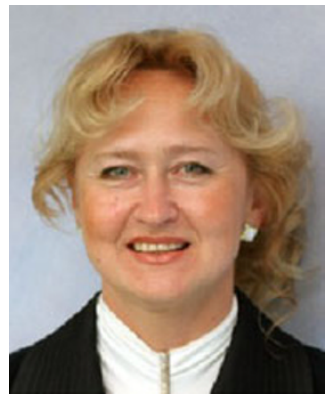

Prof. Dr. O. Golubnitschaja, Secretary-General, EPMA

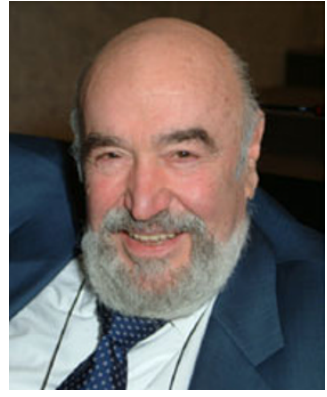

Dr. V. Costigliola, President of EPMA 


\section{HEALTHCARE IN OVERVIEW ACROSS THE GLOBE, ECONOMICS OF PERSONALISED MEDICINE}

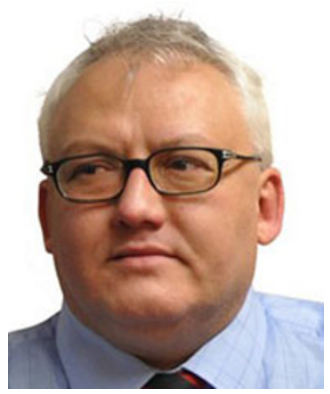

Dr. P. Bilinski, Chief of Sanitary Inspector responsible for public health in Poland

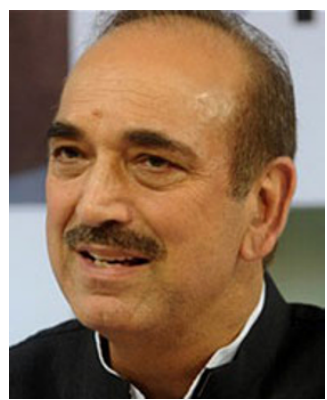

Mr. G. Nabi Azad, Minister of Health \& Family Welfare, India

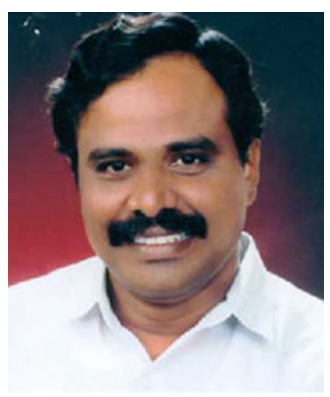

Mr. S. S. Gandhiselvan, Minister of State for Health and Family Welfare, India

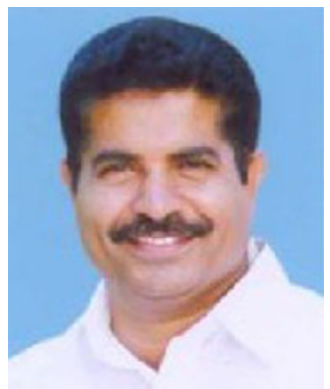

Mr. Adoor Prakash, Minister of Health, Kerala State, India

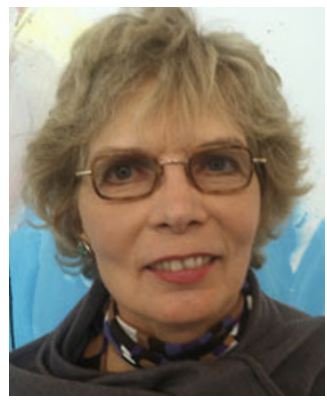

Dr. A. Benini, Missionary of the Organisation of United Nations; National Representative of EPMA in Denmark

o Dr. R. Maksimovic, Missionary of the World Health Organisation

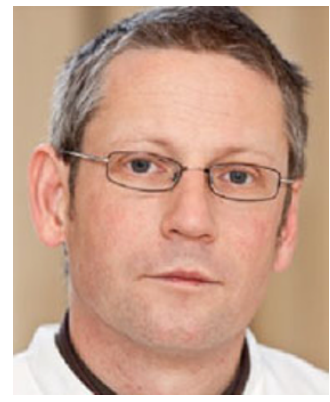

Prof. Dr. F. Paul, National Representative of EPMA in Germany

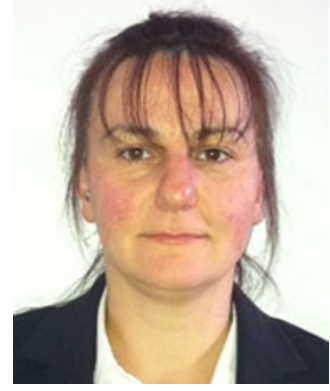

Dr. K. Grosios, National Representative of EPMA in UK

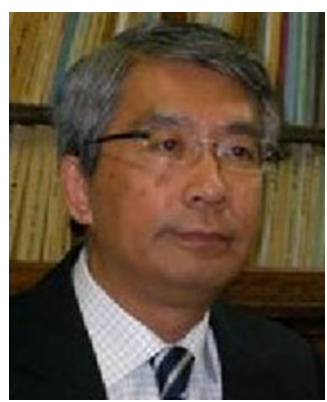

Prof. Dr. H. Iso, National Representative of EPMA in Japan 


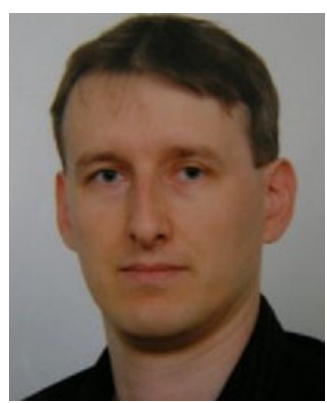

Dr. M. Kapalla, National Representative of EPMA in Slovak Republic

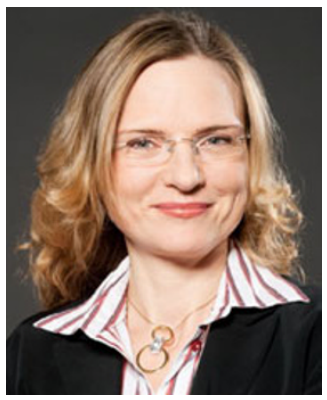

Prof. Dr. K. Richter, National Representative of EPMA in Republic of Macedonia (FYROM) and Bavaria (Germany)

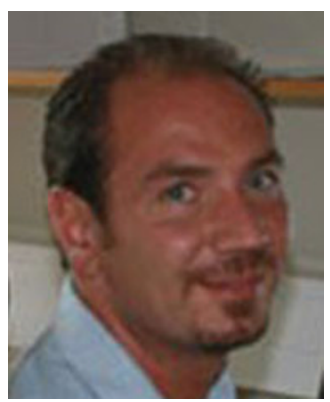

Dr. D. Dimitrov, National Representative of EPMA in Bulgaria

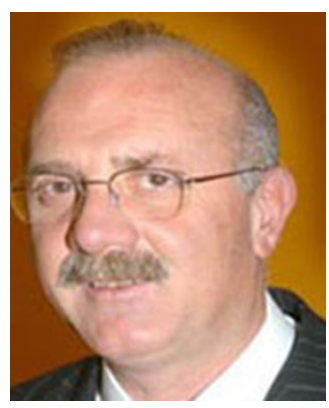

Prof. Dr. M. Dündar, National Co-Representative of EPMA in Turkey

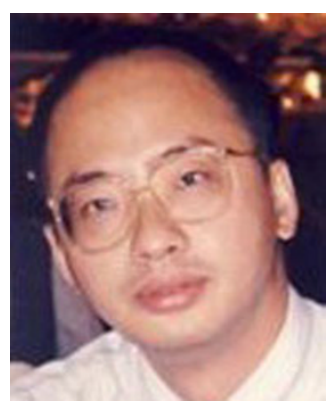

Prof. Dr. W. Sai Ho Chan, National Representative of EPMA in Taiwan (ROC)

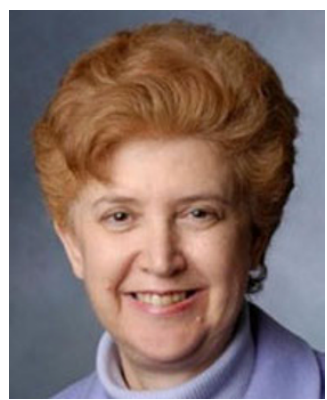

Prof. Dr. I. Gozes, National Representative of EPMA in Israel

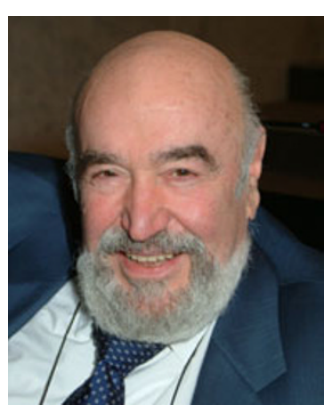

Dr. V. Costigliola, President of EPMA

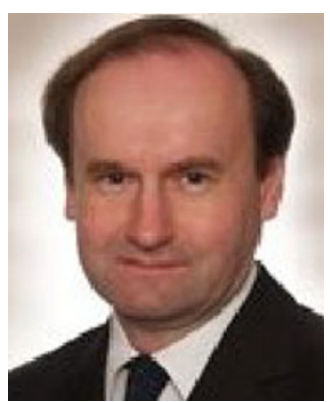

Dr. K. Krapfenbauer, Vice-President of EPMA 


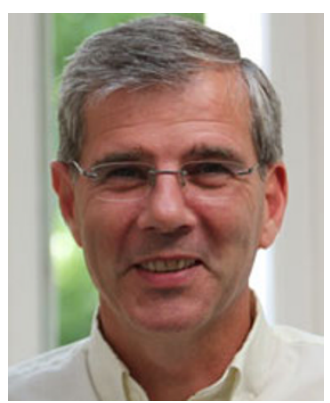

Dr. W. Spek, EuroBioForum, Managing Director, The Netherlands 


\section{GRANTING STRATEGIES IN PPPM}

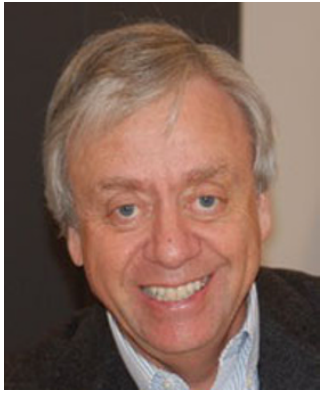

Prof. Dr. M. Goldman, Director, Innovative Medicines Initiative, EU-Commission, Brussels

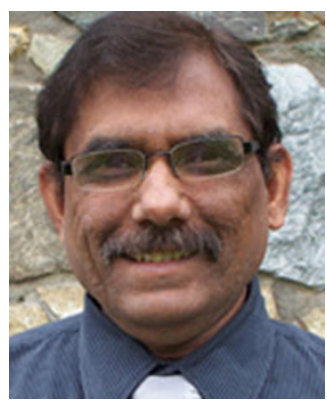

Dr. S. Srivastava, Director, Early Detection Research Network, NIH / NCI, Washington D.C., USA

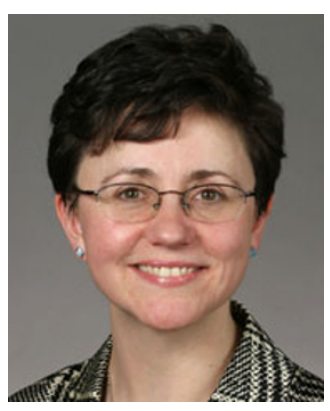

Dr. C. Longson, Director, National Institute for Health \& Clinical Excellence, UK

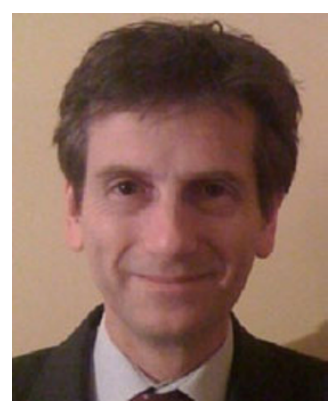

Dr. J.-L. Sanne, Directorate for Personalised Medicine, EU-Commission, Brussels, Belgium

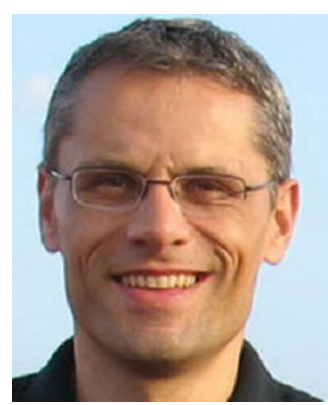

Dr. L. Kristiansen, Medical Sciences, European Science Foundation, Strasbourg, France

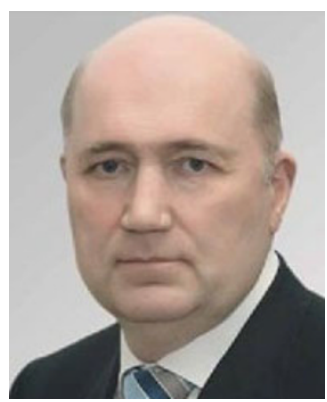

Prof. Dr. M. Paltsev, Vice-Director of the I. Kurchatov National Centre for Science and Technologies, Russia

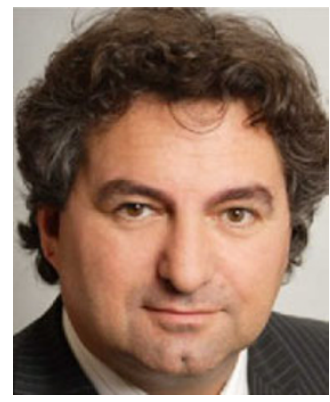

Dr. J. Greuel, Adjunct Professor of Finance \& Healthcare Management IE Business School, Madrid, Spain / Managing Director, Bioscience Valuation BSV GmbH, Germany 


\section{EDUCATION IN PREDICTIVE, PREVENTIVE AND PERSONALISED MEDICINE}

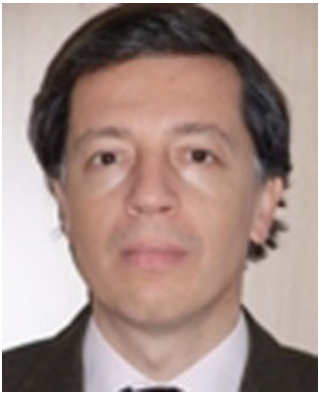

Dr. J. Delgado, Head of Unit Vocational Education and Training Policy, Leonardo da Vinci Programme, EUCommission, Brussels, Belgium

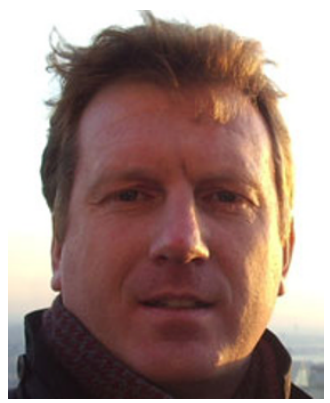

Dr. P. Butler, Editorial Director, Biomedicine, Springer

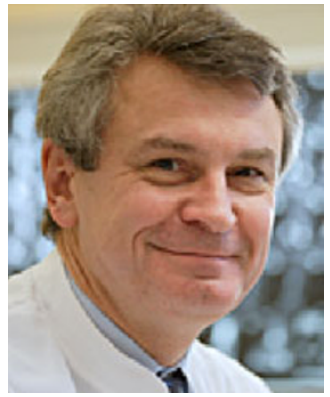

Prof. Dr. H.H. Schild, Director of Radiological Hospital, University of Bonn, Germany

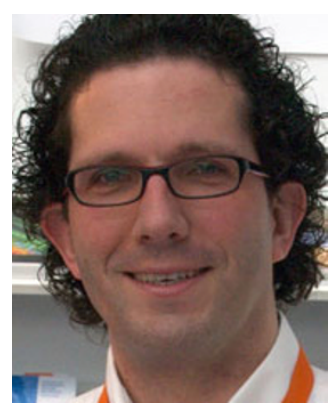

Dr. M. Roelandse, Associate Editor, Biomedical Unit, Springer

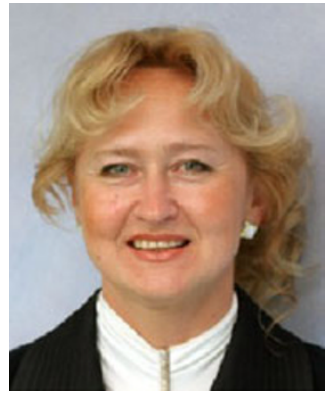

Prof. Dr. O Golubnitschaja, Editor-in-Chief, The EPMA J. \& Book-Series “Advances in PPPM", EPMA / Springer

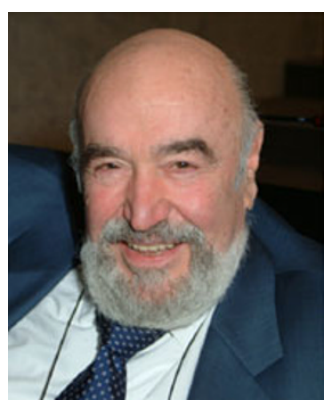

Dr. V. Costigliola, Associate Editor, The EPMA J. \& Book-Series "Advances in PPPM"

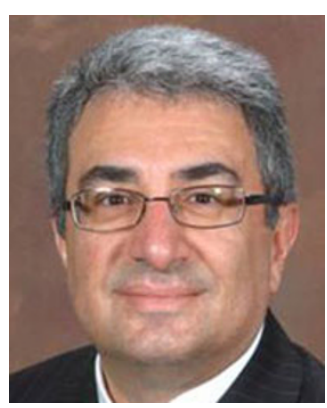

Prof. Dr. M. Mozaffari, Associate Editor, The EPMA J. \& Book-Series "Advances in PPPM"

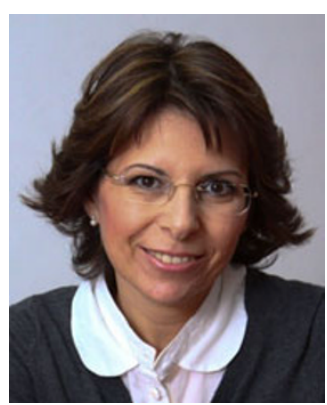

Dr. S. Mandel, Associate Editor, The EPMA J. \& BookSeries "Advances in PPPM", Vice-President of EPMA 


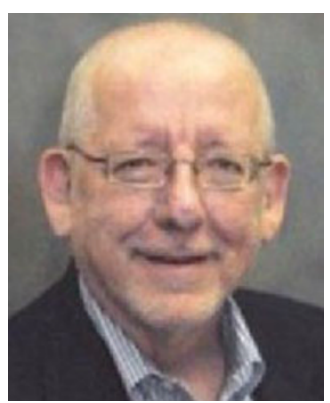

Prof. Dr. D. Desiderio, Associate Editor, The EPMA J.

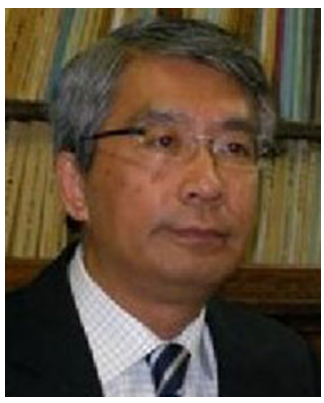

Prof. Dr. H. Iso, Associate Editor, The EPMA J.

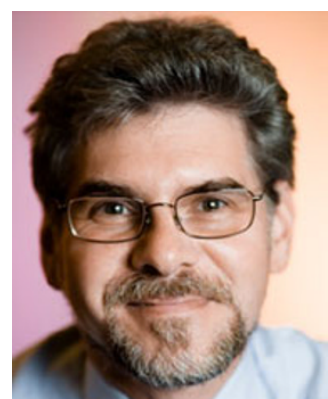

Prof. Dr. M. Scarpa, Associate Editor, The EPMA J.

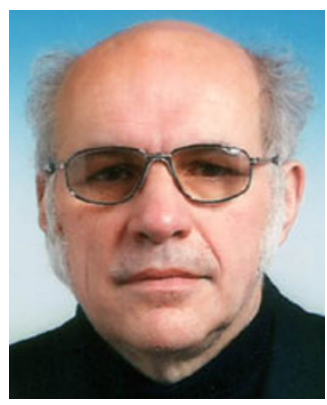

Prof. Dr. O. Topolcan, National Representative of EPMA in Czech Republic 


\section{PATIENT NEEDS - CHALLENGES FOR STAKEHOLDERS IN PREDICTIVE, PREVENTIVE AND PERSONALISED MEDICINE}

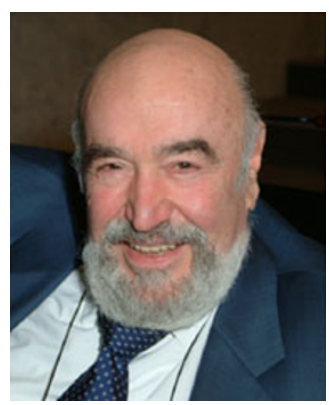

Dr. V. Costigliola, President of EPMA

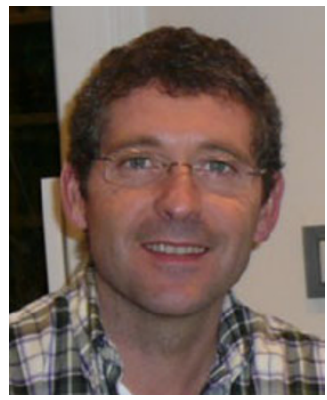

Dr. J. Mendive, National Representative of EPMA in Spain

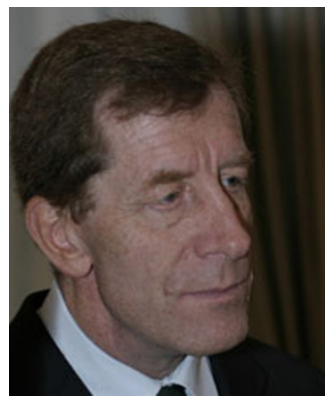

Dr. G. Vittadini, Director of Technology Opportunities, Bracco Imaging

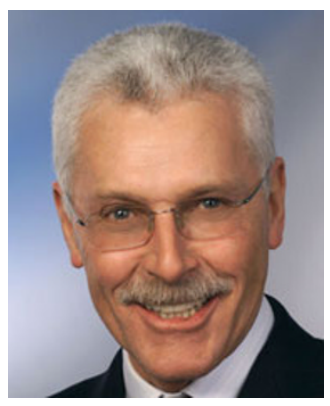

Prof. Dr. M. Reiser, ESR Past President, Professor and Chairman, Department of Radiology, Dean of the Medical Faculty, Ludwig Maximilians University Munich, Germany

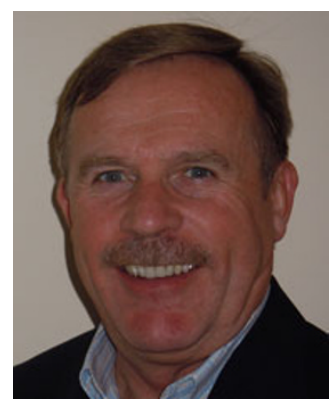

Dr. A. Jansen, Director, DiaDexus

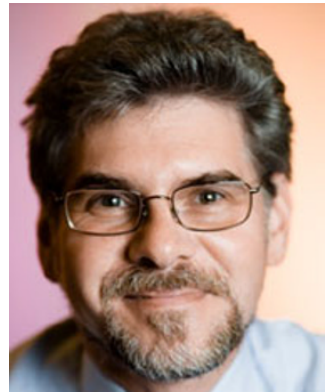

Prof. Dr. M. Scarpa, "Brains for Brain”-Foundation

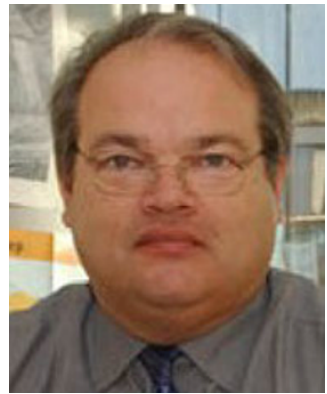

Dr. J. Bowis, President of Health First Europe, VicePresident of the European Health Forum Gastein, Chairman of the Health Advisory Board of GlaxoSmithKline

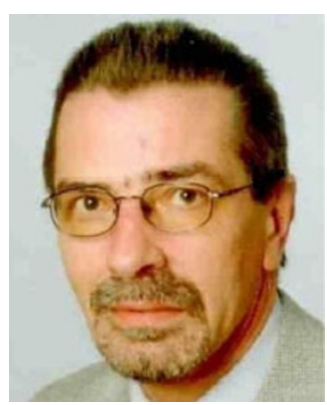

Mr. M. Hadder German Federation of Diabetics, Germany 
INNOVATIVE PPPM-CENTRES: OVERALL CONCEPT, MEDICAL IMAGING FOR DISEASE PREDICTION AND PREVENTION, INNOVATIVE DIAGNOSTIC TOOLS, NEW PERSPECTIVES IN HEALTHCARE

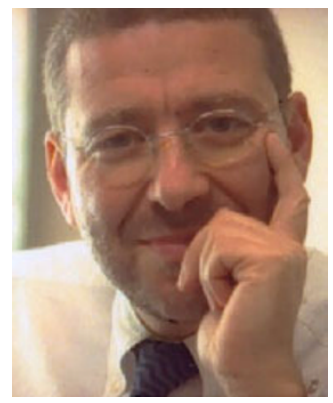

Prof. Dr. G. P. Krestin, Erasmus MC, University Medical Centre Rotterdam, The Netherlands

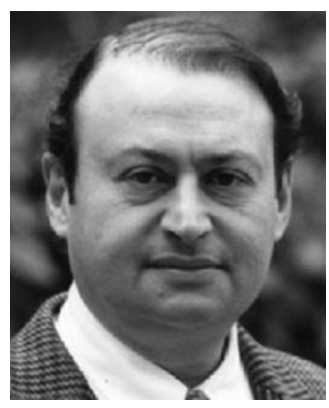

Prof. Dr. G. Frija, ESR, Paris, France

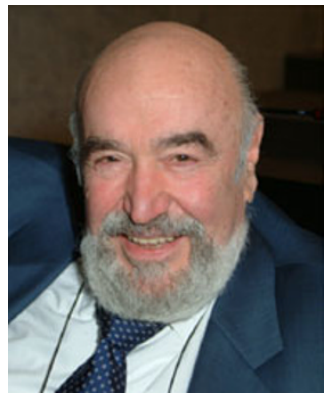

Dr. V. Costigliola, General Practitioner, Brussels, Belgium

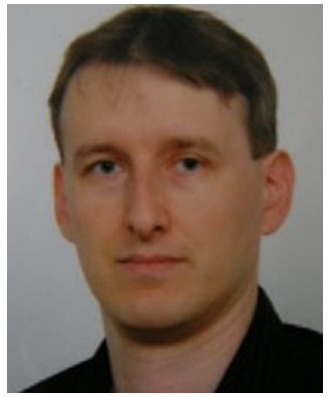

Dr. M. Kapalla, Faculty of Medicine, Comenius University, Bratislava, Slovakia; Negentropic Systems, s.r.o, Ruzomberok, Slovakia; National Representative of EPMA in Slovakia

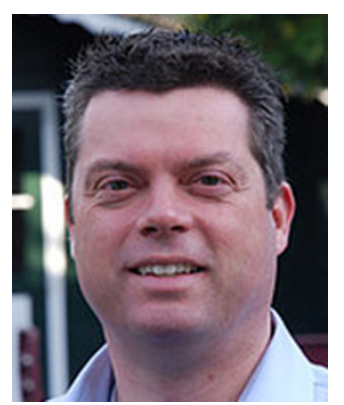

Dr. M. Pelsers, “Laboratory Stein GmbH”, Germany

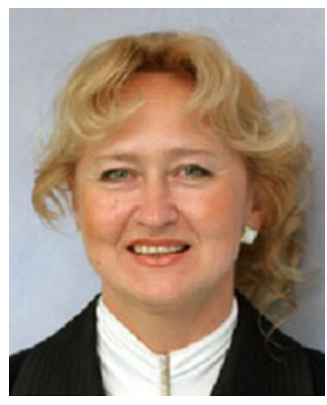

Prof. Dr. O. Golubnitschaja, Radiological Hospital, University of Bonn, Germany

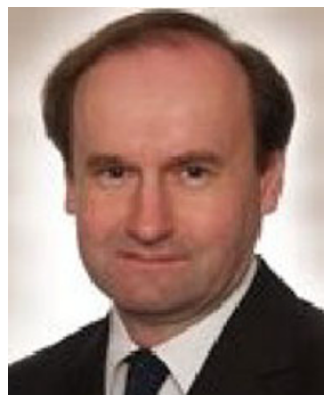

Dr. K. Krapfenbauer, Medical University of Vienna, Vienna, Austria; Vice-President of EPMA 
INFLAMMATION AND AUTOIMMUNITY: RISK ASSESSMENT AND PREDICTIVE APPROACHES THROUGH THE ANALYTICAL ARMAMENTARIUM

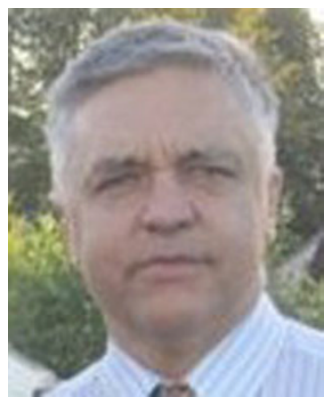

Prof. Dr. S. Suchkov, The I.M. Sechenov First Moscow State Medical University, Russian Academy of Medical Sciences, Russia

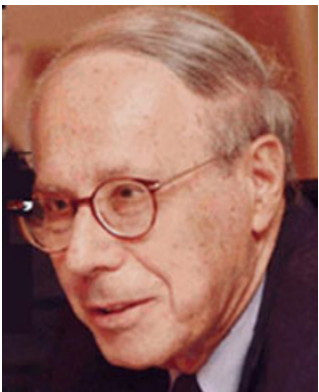

Prof. Dr. A. Notkins, Scientific Director, NIDCR / NIH, Bethesda, USA

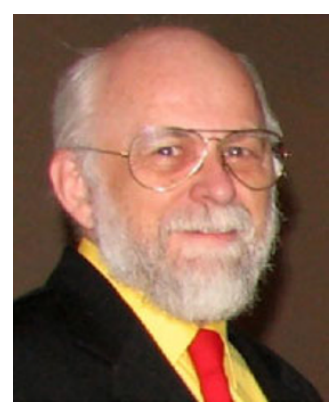

Prof. Dr. T. Marshall, Murdoch University of Western Australia 
TAILORED PREVENTION: PREDICTIVE, PREVENTIVE AND PERSONALISED CONCEPTS OF TRADITIONAL MEDICINES, PERSONALISED NUTRITION, BODY CULTURE \& SPORT MEDICINE

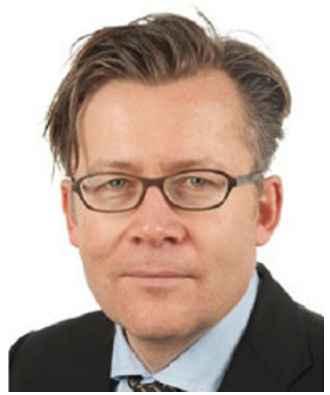

Prof. Dr. H. Boecker, University of Bonn, Germany

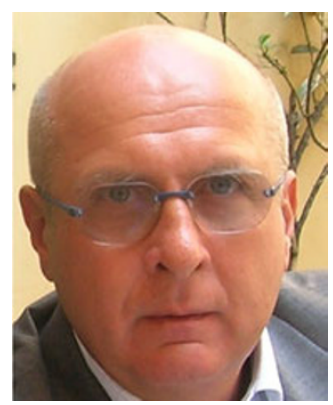

Dr. P. Roberti di Sarsina, Non-Conventional Medicine, High Council of Health, Ministry of Health, Italy

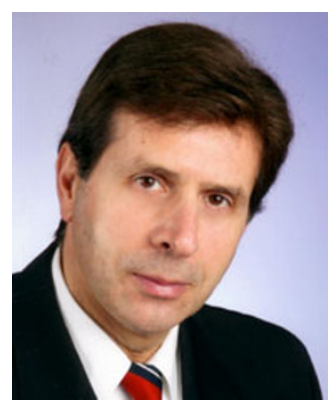

Prof. Dr. J. G. Ionescu, Specialised Clinic Neukirchen, Germany

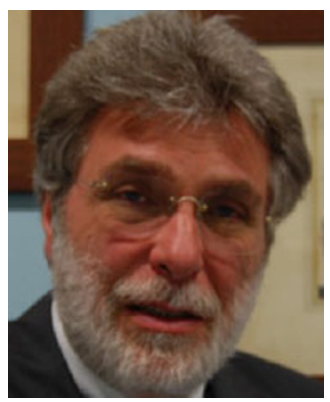

Prof. Dr. G. Trovato, Catania University, Italy

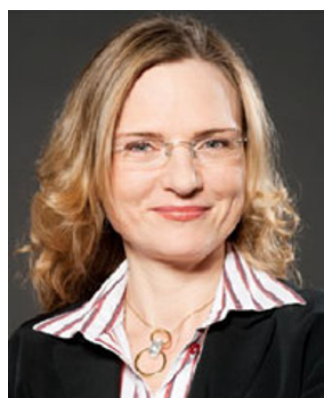

Prof. Dr. K. Richter, University of Nurnberg, Germany; National Representative of EPMA in Republic of Macedonia (FYROM) and Bavaria (Germany)

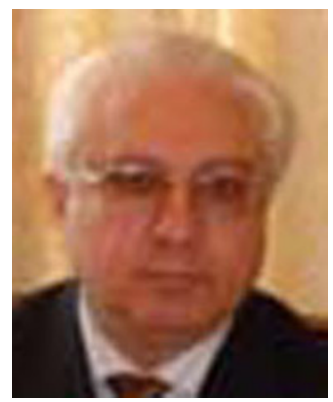

Prof. Dr. A. Kunin, The Voronezh N.N.Burdenko, State Medical Academy, Russia

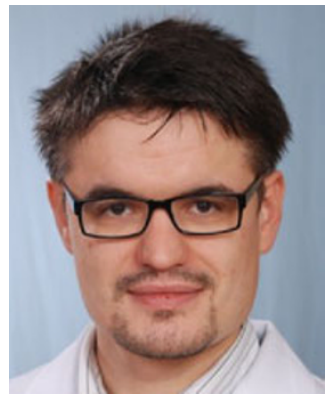

Dr. R. Bubnov, Clinical hospital, State Affairs Department of Administration of the President of Ukraine, Kiev, Ukraine; National Representative of EPMA in Ukraine 
PREDICTIVE DIAGNOSTICS AND PERSONALISED MEDICINE IN PAEDIATRICS

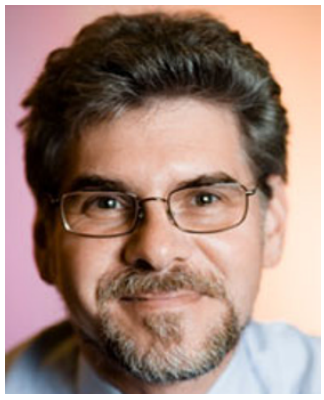

Prof. Dr. M. Scarpa, University of Padua, Italy, "Brains for Brain"-Foundation

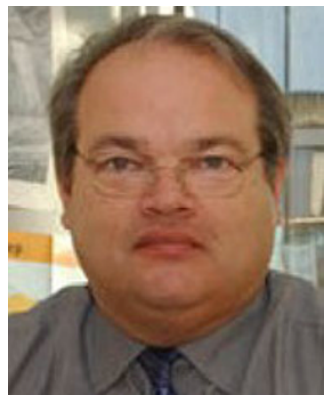

Dr. J. Bowis, President of Health First Europe, VicePresident of the European Health Forum Gastein, Chairman of the Health Advisory Board of GlaxoSmithKline

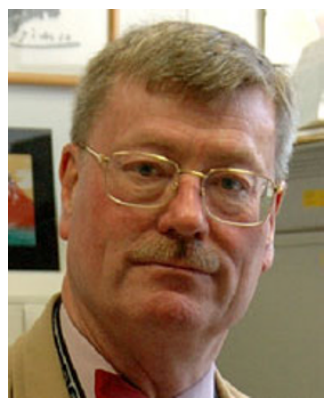

Prof. Dr. D. Begley, King's College London, UK

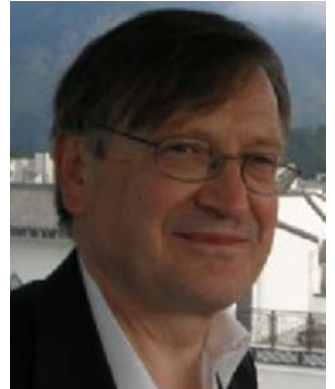

Prof. Dr. T. Cox, University of Cambridge, UK

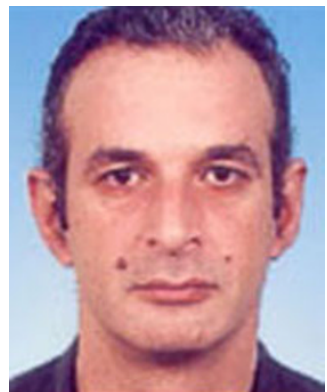

Dr. G. Tsangaris, Proteomics Research Unit, Biomedical Research Foundation, Academy of Athens, Greece; National Representative of EPMA in Greece

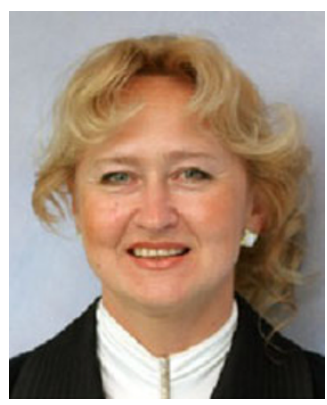

Prof. Dr. O. Golubnitschaja, University of Bonn, Germany 
PREDICTIVE, PREVENTIVE AND PERSONALISED MEDICINE IN DIABETES CARE

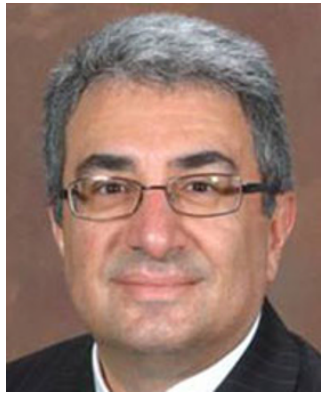

Prof. Dr. M. Mozaffari, Georgia Health Sciences University, Augusta, Georgia, USA

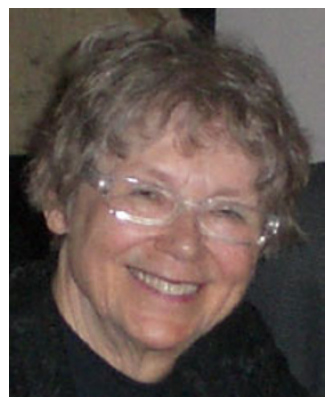

Prof. Dr. L. Salminen, Ophthalmologic Clinic, University of Tampere, Finland; National Representative of EPMA in Finland

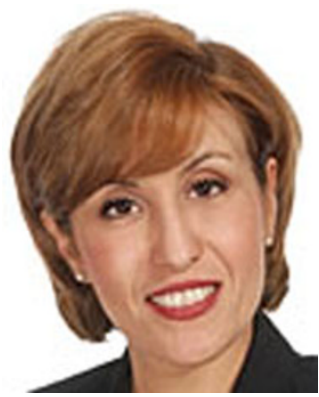

Prof. Dr. T. Josifova University Hospital Basel, Eye Clinic, Switzerland; National Representative of EPMA in Switzerland

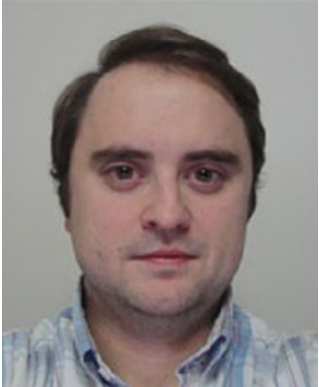

Prof. Dr. J. Coelho, Department of Chemical Engineering, University of Coimbra, Portugal; National Representative of EPMA in Portugal

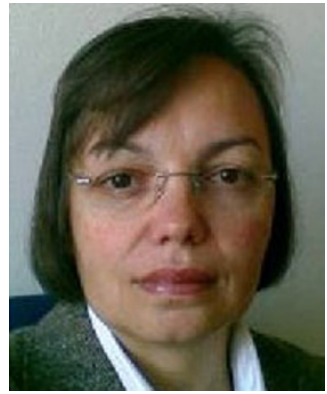

Dr. C. Sena, Medical Faculty, University of Coimbra, Portugal

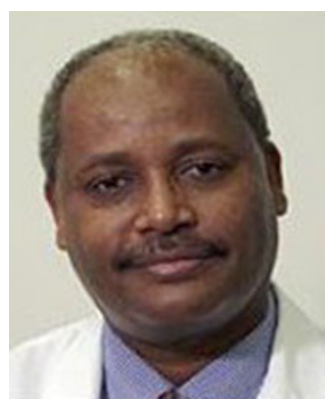

Dr. W. Abebe, Georgia Health Sciences University, Augusta, Georgia, USA

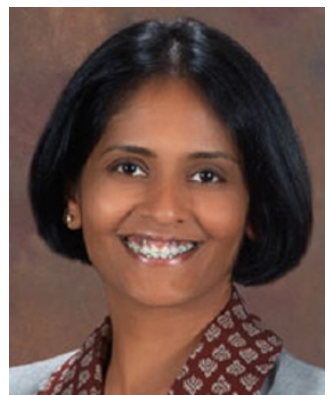

Dr. R. Krishna, Department of Periodontics, College of Dental Medicine, Augusta, USA

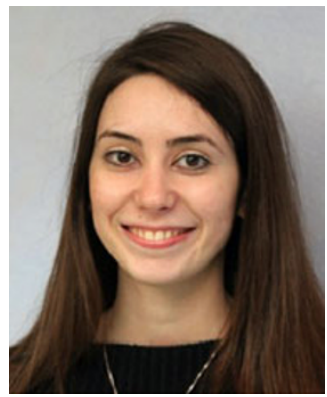

M.Sc. M. Cebioglu, Molecular Diagnostics, Department of Radiology, University of Bonn, Germany 


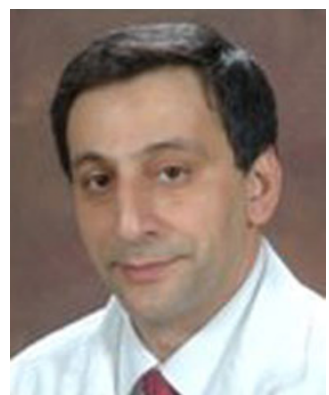

Prof. Dr. B. Baban, College of Dental Medicine, Georgia Health Sciences University, Augusta, Georgia, USA 
PREDICTIVE, PREVENTIVE AND PERSONALISED MEDICINE IN CANCER

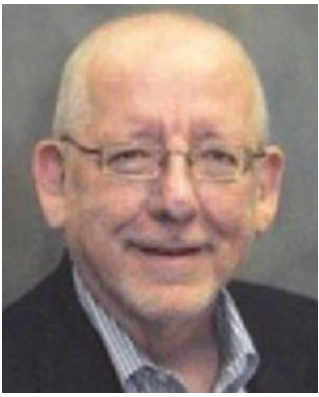

Prof. Dr. D. Desiderio, University of Tennessee Health Science Center, Memphis, USA

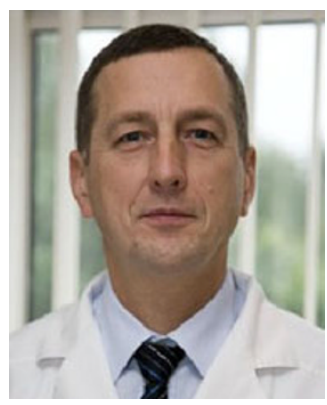

Prof. Dr. D. Characiejus, Vilnius University, Lithuania; National Representative of EPMA in Lithuania

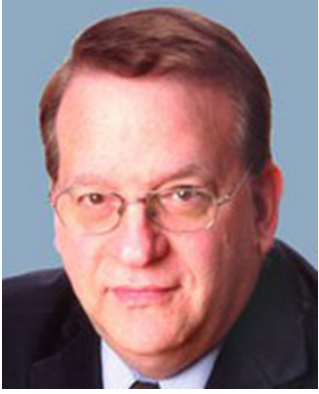

Prof. Dr. L. Berliner, Weill Cornell Medical College of Cornell University, New York, USA

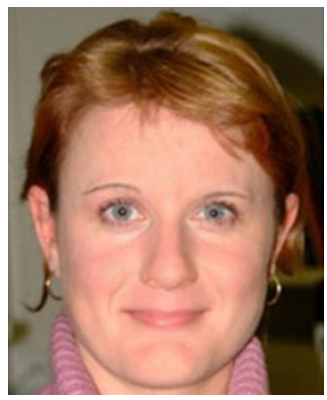

Dr. S. Hagan, Glasgow Caledonian University, Scotland

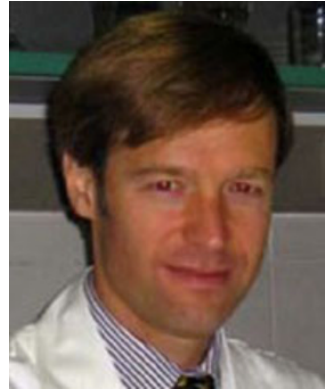

Prof. Dr. R. Danesi, University of Pisa, Italy; National Representative of EPMA in Italy

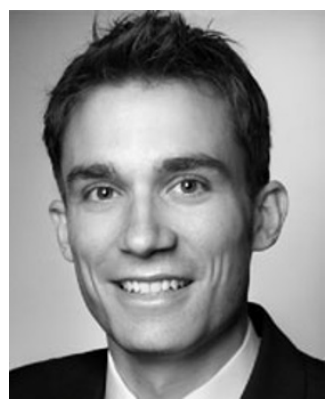

Dr. M. Mallmann, University of Bonn, Germany

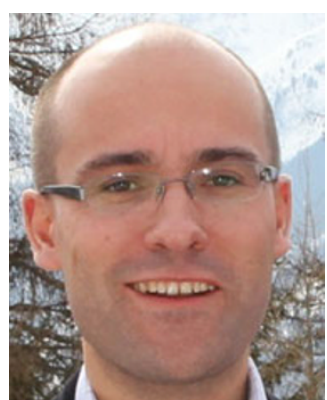

Dr. Ch. Swanton, Translational Cancer Therapeutics Laboratory, London, UK

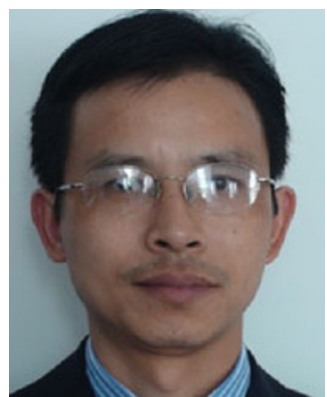

Dr. X. Zhan, University of Tennessee Health Science Center, Memphis, USA 


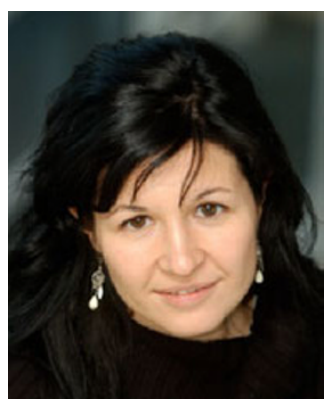

Dr. A. González Neira, Spanish National Cancer Research Centre (CNIO), Madrid, Spain; National CoRepresentative of EPMA in Spain

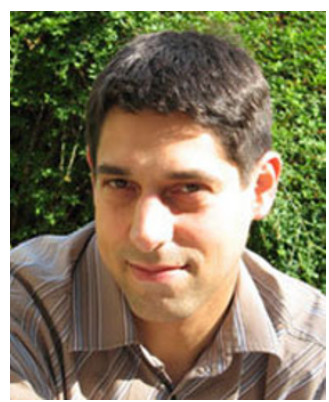

Prof. Dr. Ch. Gerner, University of Vienna, Austria; National Representative of EPMA in Austria

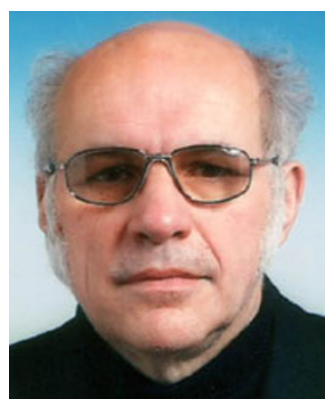

Prof. Dr. O. Topolcan, National Representative of EPMA in Czech Republic

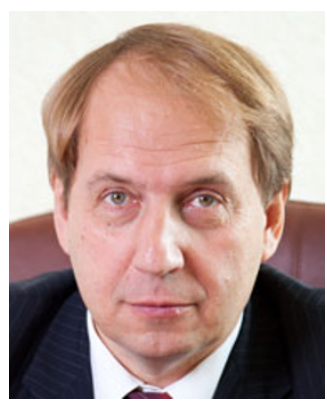

Dr. S. Kovalenko, Deputy Director, Institute of Molecular biology and Biophysics, Novosibirsk, Russia 
PREDICTIVE, PREVENTIVE AND PERSONALISED MEDICINE IN NEURODEGENERATIVE DISEASES

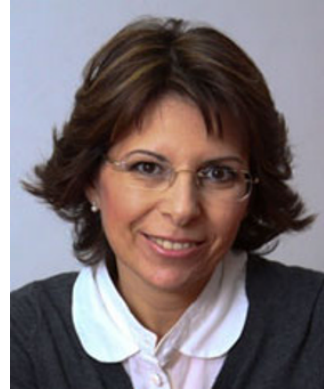

Dr. S. Mandel, Technion, University of Haifa, Israel; Vice-President of EPMA

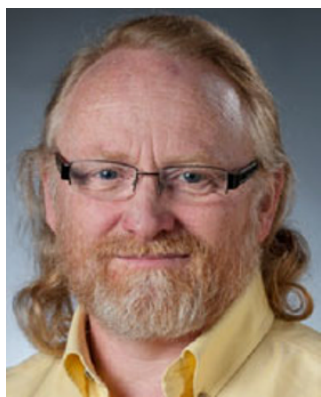

Prof. Dr. A. Tasker, University of British Columbia, Vancouver, Canada

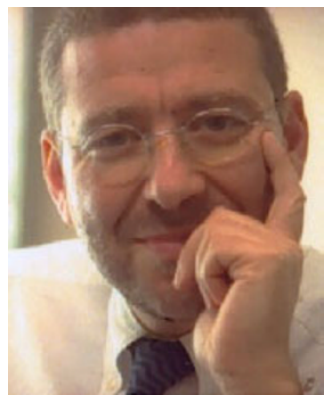

Prof. Dr. Gabriel P. Krestin, Erasmus MC, University Medical Centre Rotterdam, The Netherlands

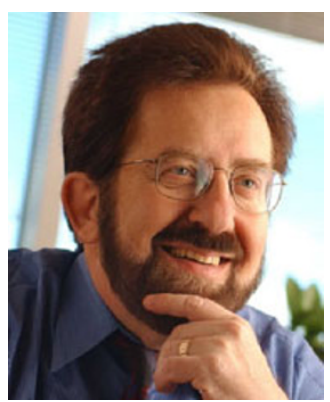

Dr. A. Roses, Duke University and Zinfandel Pharmaceuticals, Inc., USA

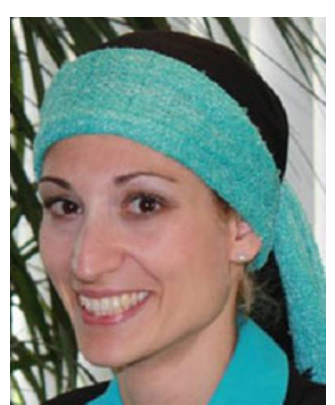

Dr. I. Grossman, Cabernet Pharmaceuticals, USA

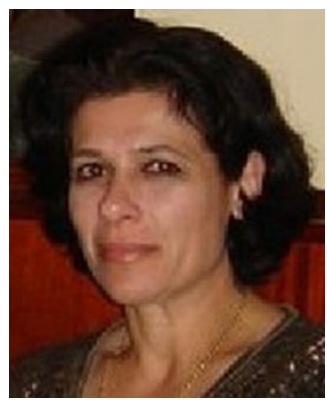

Dr. O. Weinreb, Eve Topf Centers of Excellence for Neurodegenerative Diseases Research, Rappaport Family Research Institute, Israel

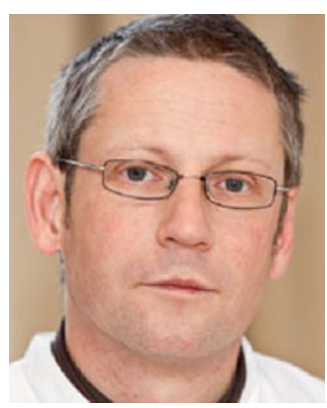

Prof. Dr. F. Paul, Charité Berlin, Germany; National Representative of EPMA in Germany

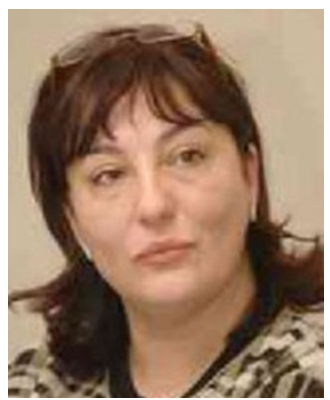

Prof. Dr. L. Spiru, President "Ana ASLAN" International Foundation, Bucharest, Romania; National Representative of EPMA in Romania 


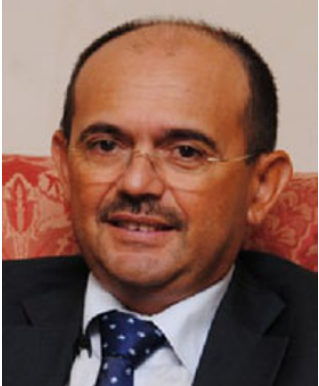

Prof. Dr. D. Muresanu, President of the Society for the Study of Neuroprotection and Neuroplasticity (SSNN), Romania; National Co-Representative of EPMA in Romania

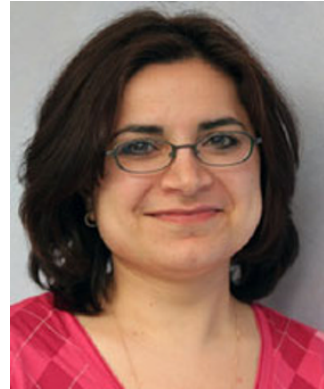

Dr. K. Yeghiazaryan, Molecular Diagnostics, Department of Radiology, University of Bonn, Germany 
PREDICTIVE, PREVENTIVE AND PERSONALISED MEDICINE IN CARDIOVASCULAR DISEASES

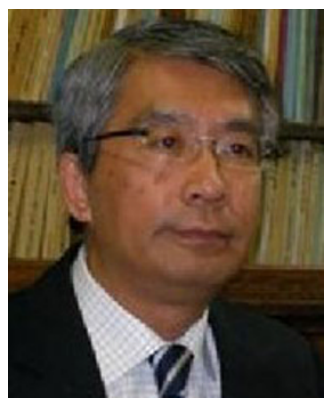

Prof. Dr. H. Iso, Osaka University, Japan; National Representative of EPMA in Japan

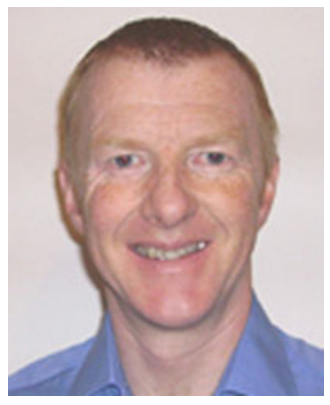

Prof. Dr. P. Evans, British Heart Foundation Cardiovascular Sciences Unit, National Heart and Lung Institute, Imperial College London, UK

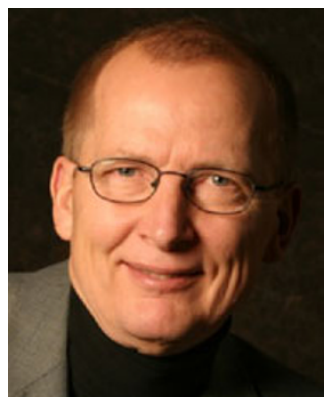

Prof. Dr. J. Kastrup, The Heart Centre, Rigshospitalet University Hospital Copenhagen, Denmark; National CoRepresentative of EPMA in Denmark

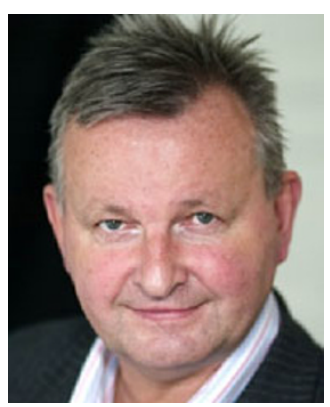

Prof. Dr. Ch. Gluud, Copenhagen University Hospital, Copenhagen, Denmark; Danish National Coordinator, ECRIN

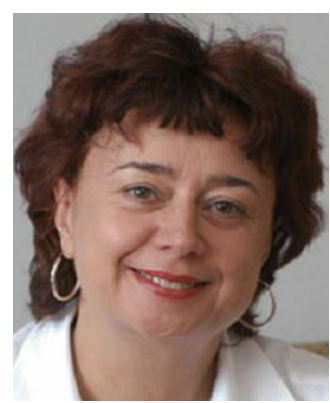

Prof. Dr. H. Rosolova, Charles University in Prague, Medical Faculty in Pilsen, Czech Republic

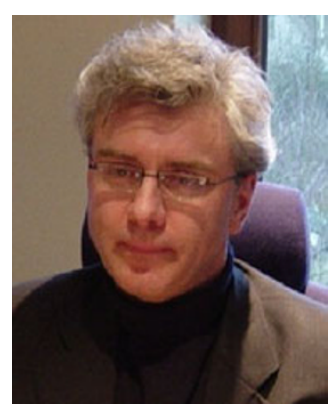

Dr. F. de Meester, DMF-PL, Gliwice, Poland

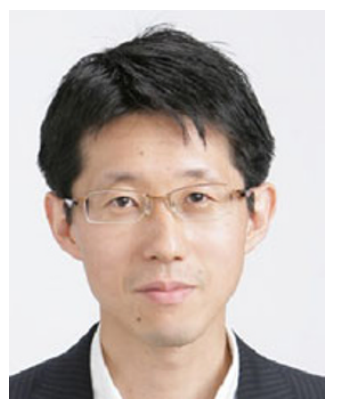

Dr. H. Yatsuya, Nagoya University, Japan

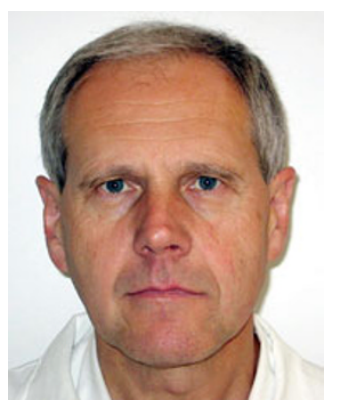

Prof. Dr. J. Polivka, Charles University in Prague, Medical Faculty in Pilsen, Czech Republic

o Dr. Y. Kokubo, Department of Preventive Cardiology, National Cerebral and Cardiovascular Center, Suita, Japan 


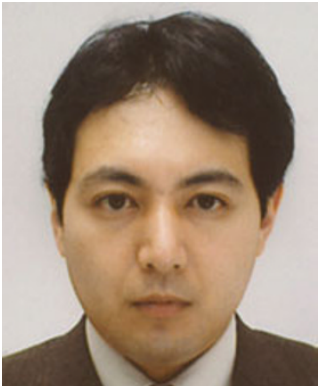

Dr. K. Yamagishi, Department of Public health Medicine, University of Tsukuba, Tsukuba, Japan 
BIOMARKER DISCOVERY, VALIDATION, STANDARDISATION AND PRACTICAL APPLICATION IN MEDICAL PRACTICE

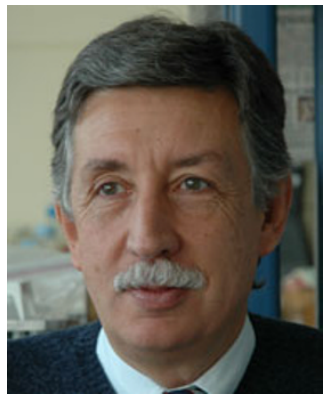

Prof. Dr. M. Ferrari, Centre for Genomics, Bioinformatics, and Biostatistics, San Raffaele Scientific Institute, Milan, Italy

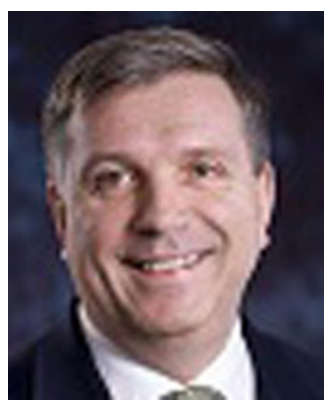

Dr. P. Jacon, EDMA Director General, Brussels, Belgium

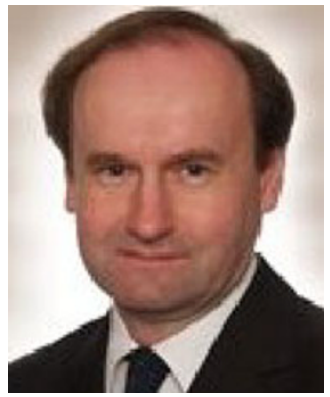

Dr. K. Krapfenbauer, Medical University of Vienna, Vienna, Austria; Vice-President of EPMA

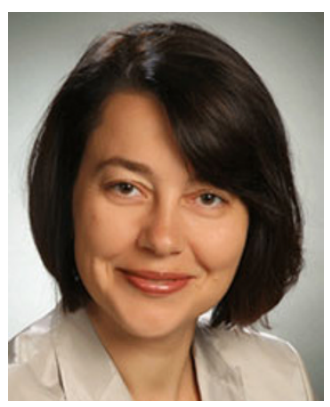

Prof. Dr. J. Kzhyshkowska, Mannheim University of Heidelberg, Germany; National Representative of EPMA in Baden Wuerttemberg (Germany)

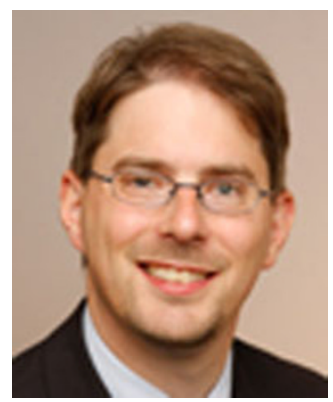

Prof. W. Lieb, Institute for Community Medicine, Ernst Moritz Arndt University Greifswald, Germany

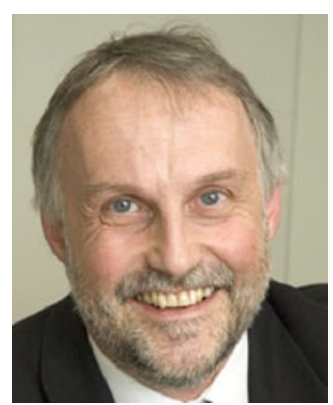

Dr. Th. Joos, NMI Natural and Medical Sciences Institute at the University of Tübingen, Germany

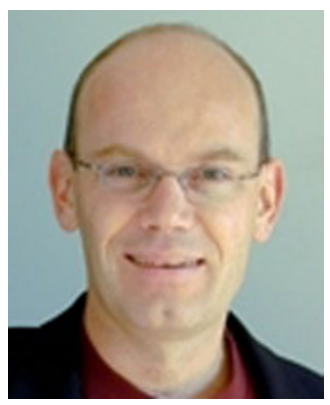

Dr. P. Schulz-Knappe, Protagen AG, Dortmund, Germany

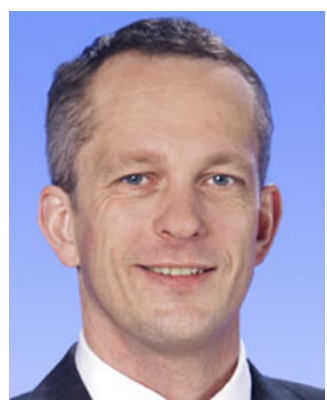

Dr. J. Walkenhorst, PROvendis, Germany 


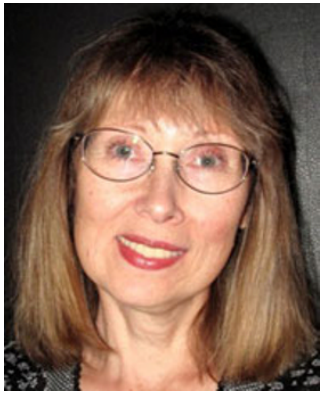

Dr. E. Moiseeva, Institute of Bioorganic Chemistry, Moscow, Russia

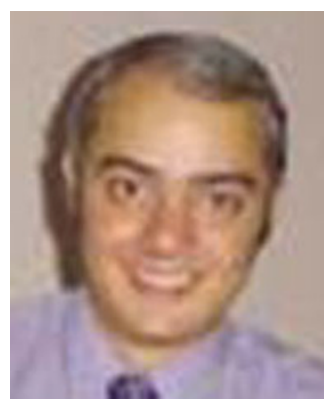

Dr. G. Grech, Faculty of Medicine and Surgery, University of Malta Medical School, Department of Pathology, Malta 
PAT I E N T-S P E C I F I C M O D E L L I N G, BIOINFORMATICS

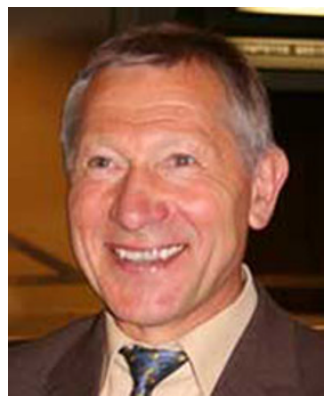

Prof. Dr. H. Lemke, Computer Assisted Radiology and Surgery, CARS

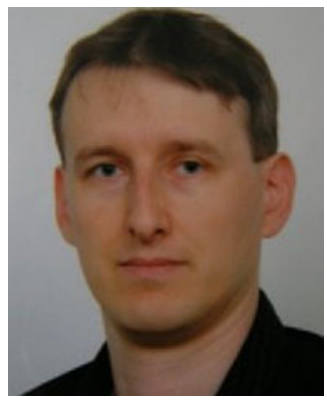

Dr. M. Kapalla, Faculty of Medicine, Comenius University, Bratislava, Slovakia; Negentropic Systems, s.ro, Ruzomberok, Slovakia; National Representative of EPMA in Slovakia

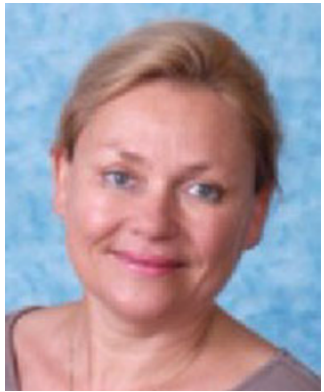

Prof. Dr. H. Podbielska, Wroclaw University, Poland; National Representative of EPMA in Poland

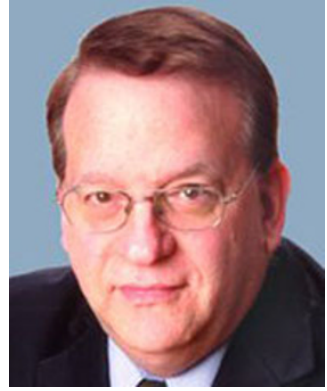

Prof. Dr. L. Berliner, Weill Cornell Medical College of Cornell University, New York, USA

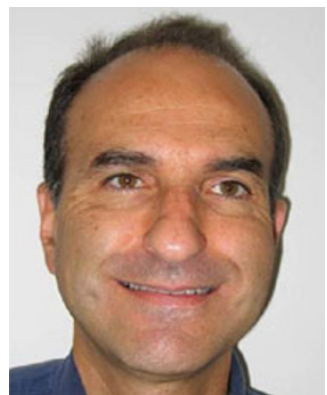

Dr. A. Shabo, IBM Research Lab in Haifa, Israel

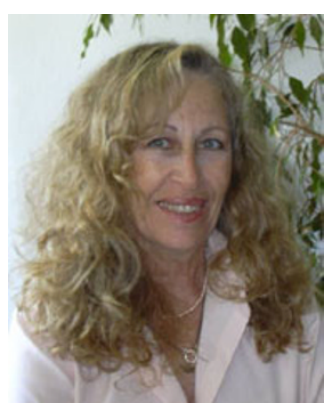

Dr. M. Marcus-Kalish, Interdisciplinary Center for Technology Analysis and Forecasting, Tel Aviv University, Israel 


\section{BIOBANKING, ETHICS}

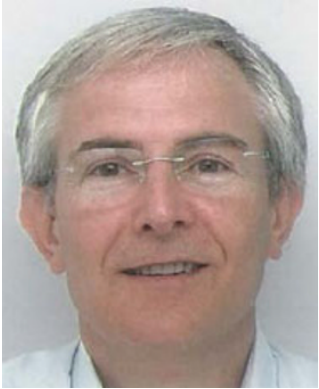

Prof. Dr. R. Hewitt, European, Middle Eastern and African Society for Biopreservation and Biobanking, France

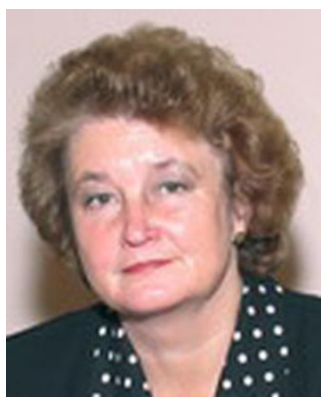

Prof. Dr. H. Everaus, Tartu University Hospital, Tartu, Estonia; National Representative of EPMA in Estonia

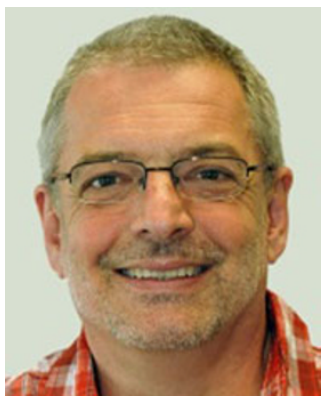

Prof. Dr. P. Riegman, Erasmus MC Tissue Bank, Erasmus MC Rotterdam, The Netherlands

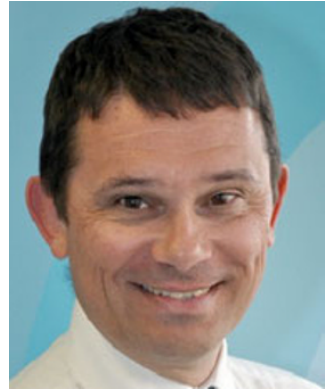

Prof. Dr. Ch. Chabannon, Institut Paoli-Calmettes \& Université d'Aix-Marseille, France

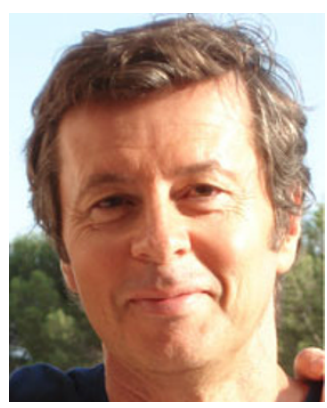

Prof. Dr. P. Hofman, Nice CHU Biobank, Pasteur Hospital, Nice, France

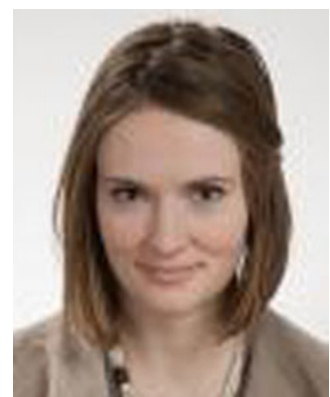

Dr. L. Leitsalu, Tartu University, Estonia 